\title{
Finger Painting dengan Olahan Kanji untuk Meningkatkan Kemampuan Melukis Anak Usia Dini
}

\section{Ida Ayu Ketut Wulan Ari Purnami ${ }^{*}$, Nice Maylani Asril ${ }^{2}$}

1,2 Prodi Pendidikan Guru Pendidikan Anak Usia Dini, Universitas Pendidikan Ganesha, Singaraja, Indonesia

\section{ART I C LE I N F O}

\section{Article history:}

Received October 28, 2021

Revised October 29, 2021

Accepted November 20, 2021

Available online December 25, 2021

Kata Kunci:

Sedia Lem, Finger Painting, Melukis

\section{Keywords:}

Glue Media, Finger Painting, Painting

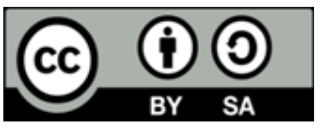

This is an open access article under the CC BY-SA license.

Copyright (ㄷ) 2021 by Author. Published by Universitas Pendidikan Ganesha.

\begin{abstract}
A B S T R A K
Pembelajaran anak usia dini memiliki jangkauan media dan alat permainan yang beragram dan hendaknya mampu menberikan pengalaman belajar yang konret untuk anak. Kegiatan yang ada dirancang khusus dan terperinci agar anak mampu mendapatkan pengalaman langsung dalam belajar dalam lingkungannya. Kegiatan finger painting menjadi kegiatan ciri khas anak usia dini yang perlu dikembangkan dengan lebih lanjut. Kegiatan finger painting yang konvensional sering membuat anak bosan dan terkesan kurang menarik. Penelitian ini bertujuan untuk menciptakan media lem kanji dalam kegiatan finger painting untuk meningkatkan kemampuan melukis anak. Jenis penelitian ini adalah penelitian pengembangan (R\&D) dengan menggunakan model ADDIE. Subjek dalam penelitian ini menggunakan 2 orang ahli media, 2 orang ahli materi, dan 2 ahli judges instrument. Pengumpulan data dalam penelitian ini menggunakan metode angket yang kemudian dianalisis menggunakan analisis data yaitu data kuantitatif dan kualitatif. Media lem kanji dinyatakan valid dari para ahli dengan rata-rata nilai CVR 1,00 dan CVI 1,00. Dari hasil tersebut dapat disimpulkan bahwa pengembangan media lem kanji dalam kegiatan finger painting untuk meningkatkan kemampuan melukis anak mendapatkan hasil validitas sangat tinggi sehingga media lem kanji dalam kegiatan finger painting layak untuk diimplementasikan dalam pelajaran anak usia dini. Pengembangan ini diharapkan dapat menjadi referensi kegiatan finger painting yang inovatif dan ramah lingkungan.
\end{abstract}

\section{A B S T R A C T}

Early childhood learning has a variety of media and game tools and should be able to provide concrete learning experiences for children. Existing activities are specifically designed and detailed so that children can get direct experience in learning in their environment. Finger painting activities are characteristic of early childhood activities that need to be developed further. Conventional finger painting activities often make children bored and seem less attractive. This study aims to create starch glue media in finger painting activities to improve children's painting skills. This type of research is development research (R\&D) using the ADDIE model. The subjects in this study used 2 media experts, 2 material experts, and 2 judges instrument experts. The data collected in this study used a questionnaire method which was then analyzed using data analysis, namely quantitative and qualitative data. The starch glue media was declared valid by the experts with an average CVR value of 1.00 and CVI 1.00. From these results, it can be concluded that the development of starch glue media in finger painting activities to improve children's painting skills gets very high validity results so that starch glue media in finger painting activities is feasible to be implemented in early childhood lessons. This development is expected to be a reference for innovative and environmentally friendly finger painting activities.

\section{PENDAHULUAN}

Pendidikan anak usia dini merupakan upaya pembinaan yang ditujukan pada anak usia dini sejak lahir sampai dengan usia enam tahun yang dilakukan melalui pemberian rangsangan pendidikan untuk membantu tumbuh kembang jasmani dan rohani agar anak siap dalam memasuki pendidikan lebih lanjut. Pendidikan usia dini juga merupakan pendidikan yang utama, sehingga sering disebut sebagai masa emas (golden age), karena pada usia dini merupakan masa emas untuk anak belajar semua hal yang penting dan 
menunjang tumbuh kembang potensi dan aspek perkembangan anak, diantaranya aspek fisik motorik, kognitif, bahasa, sosial, emosi, serta apek agama moral (Handayani et al., 2018). Sehingga, dalam masa usia dini sangat penting untuk memberikan berbagai stimulasi untuk menunjang dan memaksimalkan tumbuh kembang anak, terutama di masa peka anak usia dini. Pembelajaran anak usia dini erat kaitannya dengan bermain. Dunia anak adalah bermain, dan bermain adalah dunia anak. Bermain merupakan sarana untuk belajar anak. Bermain merupakan salah satu aktivitas menyenangkan yang dilakukan, dan demi aktivitas itu sendiri, bermain memiliki fungsi dan bentuk. Bermain adalah membawa harapan dan antisipasi tentang dunia yang memberikan kegembiraan, dan memungkinkan anak berkhayal seperti sesuatu atau seseorang, suatu dunia yang dipersiapkan untuk berpetualang dan mengadakan telaah, melalui bermain anak belajar mengendalikan diri sendiri, memahami kehidupan, memahami dunianya (Desai \& Nomlomo, 2014). Sehingga, bermain merupakan suatu aktivitas yang menyenangkan yang dapat mengembangkan imajinasi anak serta anak juga dapat belajar mengendalikan diri sendiri melalui bermain (Sartika et al., 2018; Erasmus et al., 2018; Reed, 2019).

Banyak kegiatan yang bisa dikembangkan dari bermain. Salah satu kegiatan yang disenangi anak adalah kegiatan fingers painting. Fingers painting adalah teknik melukis dengan mengoleskan cat berwarna-warni pada kertas dengan jari tangan secara langsung tanpa menggunakan bantuan alat atau kuas (Desai \& Nomlomo, 2014). Dalam kegiatan fingers painting, anak dapat dengan bebas menuangkan imajinasi yang akan diwujudkannya. Fingers painting dapat mengembangkan ekspresi melalui media lukis dan gerak jari dan tangan, mengembangkan fantasi, imajinasi dan kreasi, melatih otot-otot tangan dan jari, kecakapan kombinasi warna, memupuk perasaan terhadap gerakan tangan, dan memupuk keindahan (Bipath \& Nkabinde, 2018; Nshimbi et al., 2020; Rudolph et al., 2019). Aktivitas ini penting dilakukan karena memberikan sensasi pada jari sehingga dapat menekan kontrol gerakan jarinya dan membentuk konsep gerak membuat huruf serta untuk melatih koordinasi tangan dan matanya. Selain itu, fingers painting juga meningkatkan kemampuan berpikir dan kreativitas anak, mengembangkan kemampuan dalam mengungkapkan nilai-nilai estetika dengan menggambar karyanya kreatif dan melatih otot-otot jari (Fachrurrazi \& Setyaningsih, 2019). Kegiatan fingers painting yang sudah dilakukan sebelumnya mengarah pada melukis dengan menggunakan warna-warna primer. Tekstur yang digunakan kurang beragam, dan media yang digunakan bersifat seadanya karena harus menyesuaikan dengan penganggaran kegiatan disekolah. Berdasarkan hasil observasi dan wawancara yang dilakukan, bahwa finger painting yang dilakukan disekolah jarang dilakukan, selain karena anggaran yang terbatas, anak juga terlihat bosan ketika terdapat kegiatan fingers painting. Hal ini disebabkan warna yang disediakan monoton dan sedikit, Jadi, anak merasa terhambat untuk melukis. Sehingga, kegiatan fingers painting ini terkesan membosankan dan kurang bermakna. Hal ini menyebabkan kegiatan melukis kurang diminati oleh anak, dan guru menjadi kesulitan untuk mengembangkan kegiatan lain yang sejenis dengan melukis. Selain itu, guru juga mempunyai hambatan dalam menyiapkan perlengkapan melukis karena anak cepat bosan dan kurang berminat pada kegiatan melukis yang konvensional, kemudian peralatan cat yang lumayan mahal, serta diperlukan dalam jumlah yang banyak. Sehingga, dari observasi yang dilakukan dipandang perlu adanya pengembangan bahan melukis yang mudah dibuat dan ramah lingkungan bagi anak, sebagai upaya untuk berinovasi untuk menumbuhkan kembali minat melukis pada anak.

Melukis penting untuk difasilitasi dengan baik, karena dalam kegiatan melukis melibatkan koordinasi mata dengan motorik halus. Koordinasi mata dan motorik halus ini penting untuk distimulasi sebagai bekal keterampilan seni, dan menulis permulaan anak (Hasibuan \& Ningrum, 2017; Maghfuroh \& Putri, 2018). Ketika mengembangkan kegiatan fingers painting, guru hendaknya bisa berkreasi semaksimal mungkin untuk menyediakan alat dan bahan agar kegiatan berjalan dengan lancar dan menyenangkan (Armstrong, 2015; Philpott \& Muthukrishna, 2019; Van Heerden, 2016). Tidak terbatas pada pembiayaan, guru bisa membuat alat dan bahan dari materi yang ada di sekitar lingkungan sekolah, khususnya dalam mengkreasikan warna-warna yang akan dibuat. Salah satu pengembangan bahan warna yang bisa dilakukan adalah warna dengan olahan kanji (tepung tapioka). Olahan kanji ini dibuat dari tepung tapioka yang dilelehkan, bertekstur lengket, dan dapat menyerap warna dengan baik (Ayuni \& Setiawati, 2019; Prima \& Lestari, 2018; Zaini \& Soenarto, 2019). Hasilnya, selain mempunyai tekstur yang dapat dirasakan anak, olahan kanji ini juga mampu menyatu dengan warna primer (Suciati et al., 2016). Selain bagus untuk kegiatan fingers painting, bahan dan cara membuatnya pun mudah, cukup didihkan kanji, dinginkan, dan tambahkan warna primer. Olahan kanji juga mudah didaur ulang dan ramah lingkungan. Metode bermain fingers painting dapat meningkatkan kemampuan motorik halus anak. Hal ini dapat dilihat dari dari hasil penelitian pada siklus I persentase kemampuan motorik halus anak sebesar 65,93\% yang berada pada kategori sedang. Penelitian dilanjutkan dengan melakukan perbaikan pada siklus II dan mengalami peningkatan dengan persentase kemampuan motorik halus anak sebesar 82,93\% yang berada pada kriteria tinggi. Jadi terjadi peningkatan kemampuan motorik halus anak dari siklus I ke siklus II sebesar $17 \%$. Kreativitas anak kelompok A1 RA Averrous Bogoran dapat ditingkatkan melalui kegiatan fingers painting. 
Penelitian ini berhasil meningkatkan kreativitas anak untuk memberikan ide gambar dan warna, melakukan pencampuran warna dan memodifikasi gambar, membuat karya dari ide anak sendiri dan menghasilkan karya yang berbeda, serta mengembangkan ide dari karyanya. Data pada pra-tindakan yang menunjukkan persentase kreativitas anak adalah 48, 65 \%. Pada siklus I persentase kemampuan kerja sama anak meningkat menjadi 64,95\%. Pada Siklus I persentase kemampuan kerja sama anak meningkat menjadi 87,05\% (Wahyuni \& Erdiyanti, 2020). Selain itu, mengembangkan seni lukis pada anak kelas B TK Bunda Kandung, Kabupaten Aceh Besar dapat dikembangkan melalui kegiatan fingers painting. Hal tersebut dapat dilihat dari upaya penerapan yang telah lakukan dengan memberikan kegiatan membuat lukisan sesuai contoh gambar menggunakan finger painting kepada anak sebanyak 2 siklus, yang mana pada setiap siklus terdiri dari 2 pertemuan. Proses pembelajaran pada siklus I menunjukkan sebagian anak dalam membuat lukisan menggunakan fingers painting masih dibantu, ada anak yang tidak mau memegang adonan dari Finger painting. Pada pembelajaran siklus II menunjukkan hampir semua anak membuat lukisan sesuai contoh gambar menggunakan fingers painting tanpa bantuan dan semua anak mengerjakan kegiatan melukis yang telah diberikan. Penelitian ini bertujuan untuk mengembangkan media olahan kanji dalam kegiatan finger painting sebagai upaya untuk meningkatkan kemampuan melukis anak usia dini, dengan berbasis bahan ramah lingkungan. Pengembangan media lem kanji menjadi rekomendasi karena lem kanji merupakan bahan ramah lingkungan dan mudah didapatkan serta diolah. Sehingga penulis berharap pengembangan ini dapat menjadi referensi bagi pengembang atau peneliti lain terkhusus dalam bidang PAUD.

\section{METODE}

Metode Penelitian ini menggunakan jenis penelitian pengembangan atau Research and Development dengan model ADDIE (Ningsih, 2020). Tahap analisis (analyze) adalah tahapan pertama yaitu menganalisis perlu adanya pengembangan media untuk menunjang kemampuan melukis. Kemudian tahap kedua perencanaan (design) yaitu tahapan membuat desain dari kebutuhan; menentukan tema untuk kegiatan finger painting untuk meningkatkan kemampuan melukis; dan mempersiapkan alat dan bahan yang digunakan dalam kegiatan finger painting menggunakan media lem kanji untuk meningkatkan kemampuan melukis. Selanjutnya tahap ketiga yaitu pengembangan (development) sebagai realisasi rancangan produk dalam hal ini adalah media lem kanji. Setelah itu media yang akan digunakan dalam kegiatan Fingers Painting untuk meningkatkan kemampuan melukis ini akan divalidasi oleh dosen ahli media. Validasi ini sangat penting dilakukan agar dapat menguji produk yang akan dikembangakan dan untuk mengetahui apakah produk tersebut layak digunakan atau tidak. Uji validitas yang dilakukan penelitian meliputi uji validitas ahli materi dan validasi ahli media. Selanjutnya implementasi, pada tahap ini media lem kanji akan diterapkan dalam pembelajaran dan akan diuji coba terlebih dahulu, uji coba untuk mengetahui apakah kegiatan bermain finger painting menggunakan media lem kanji ini dapat meningkatkan kemampuan melukis (namun tahap ini ditiadakan karena terkendala pandemi covid-19). Kemudian tahap evaluasi, tahap evaluasi merupakan tahapan terakhir yang dilakukan setelah implementasi kegiatan finger painting menggunakan media lem olahan kanji untuk meningkatkan kemampuan melukis. Tahap evaluasi dilakukan untuk memperbaiki media yang digunakan dengan saran yang diberikan oleh ahli. Pengumpulan data dilakukan dengan kuesioner. Kisi-kisi dari instrument yang digunakan dalam pengumpulan data disajikan pada Tabel 1,2 dan 3.

Tabel 1. Kisi-Kisi Kemampuan Melukis

\begin{tabular}{|c|c|c|}
\hline \begin{tabular}{l}
\multicolumn{1}{c}{ Variabel } \\
Kemampuan \\
melukis
\end{tabular} & Dimensi & Indikator \\
\hline \multirow{8}{*}{$\begin{array}{l}\text { Kemampuan } \\
\text { melukis }\end{array}$} & Pencampuran & 1. Anak mampumencampurkan warna primer \\
\hline & Warna & $\begin{array}{l}\text { 2. Anak mampu melukis dengan menggunakan warna yang } \\
\text { ditentukan dengan tangan }\end{array}$ \\
\hline & & 3. Anak mampu melukis pada kertas menggunakan gradasi warna \\
\hline & $\begin{array}{l}\text { Mengembangkan } \\
\text { kreativitas }\end{array}$ & $\begin{array}{l}\text { 1. Anak mampu mempraktekan gambar yang dicontohkan oleh } \\
\text { guru }\end{array}$ \\
\hline & & 2. Anak mampu mengekspresikan hasil gambar tanpa contoh guru \\
\hline & $\begin{array}{l}\text { Melatih } \\
\text { ketelitian, }\end{array}$ & $\begin{array}{l}\text { 1. Anak mampu melakukan fingerpainting dengan rapi tanpa ada } \\
\text { adonan lem kanji yang tercecer }\end{array}$ \\
\hline & $\begin{array}{l}\text { kesabaran, dan } \\
\text { rasa keindahan }\end{array}$ & $\begin{array}{l}\text { 2. Anak mampu menggoreskan adonan lem kanji yang sudah } \\
\text { tercampur wara pada kertas }\end{array}$ \\
\hline & & $\begin{array}{l}\text { 3. Anak mampu melukis pada kertas sesuai dengan tema yang } \\
\text { ditentukan }\end{array}$ \\
\hline
\end{tabular}


Tabel 2. Kisi-Kisi Instrumen Ahli Materi

\begin{tabular}{lllll}
\hline No & \multicolumn{1}{c}{ Instrumen } & & \multicolumn{3}{c}{ Indikator } & \\
\hline 1 & Kurikulum & 1. & Kesesuaian materi & \\
2 & Tujuan & 2. & FingerPainting menggunakan lem kanjisesuai & untuk \\
& & & meningkatkan kemampuan melukis anak & \\
3 & Isi materi & 3. & Judul sesuai dengan materi yang disampaikan & \\
4 & Kejelasan materi & 4. & Kejelasan materi terhadap kegaiatan yang dilakukan & \\
5 & Bahasa & 5. & Bahasa yang digunakan mudah dipahami dan dimengerti & \\
5 & Motivasi & 6. & Materi yang disampaikan dapat memotivasi belajar anak & \\
\hline
\end{tabular}

Tabel 3. Kisi-Kisi Instrumen Ahli Media

\begin{tabular}{clll}
\hline No & Instrumen & & \multicolumn{1}{c}{ Indikator } \\
\hline 1 & Teknis & 1. & Kemudahan penggunaan produk media lem kanji \\
& & 2. & Produk praktis dan mudah digunakan \\
& & 3. & Dapat digunakan dalam waktu jangka lama \\
2 & Tampilan & 4. & Produk dikemas dengan menarik \\
& & 5. & Kemenarikan produk \\
\hline
\end{tabular}

Untuk menguji validitas konstruksi, ahli berperan penting dalam memvalidasi (experts judgment). Subjek dalam penelitian ini menggunakan 2 orang ahli media, 2 orang ahli materi, dan 2 ahli judges instrument. Setelah instrument divalidasi lalu dihitung dengan rumus dan tabulasi silang gregory. Skor yang didapatkan kemudian dirata-ratakan untuk mengetahui validitas media lem kanji dengan menggunakan rumus Content Validity Ratio (CVR). Setelah mengidentifikasi setiap sub pertanyaan isntrumen dengan menggunakan CVR, maka selanjutnya yaitu melakukan perhitungan CVI (Content Validity Index). Untuk menghitung rata-rata digunakan CVI dari keseluruhan nilai CVR.

\section{HASIL DAN PEMBAHASAN}

Hasil

Pengembangan media lem kanji dilaksanakan menggunakan model ADDIE dengan melalui beberapa tahap yakni, analisis, perancangan, pengembangan, implementasi dan evaluasi. Namun ada beberapa tahap yang tidak dapat terlaksana yaitu, implementasi dan evaluasi. Hal ini dikarenakan keterbatasan waktu, kenaga sumber daya, dan finasial. Media lem kanji dikembangkan berdasarkan hasil analisis kebutuhan. Adapun hasil dari pengembangan produk yang menggunakan model ADDIE. Hasil pengembangan media lem kanji melalui beberapa prosedur yaitu, analisis, perancangan, dan pengembangan. Pada tahap analisis, yang dilakukan olh penulis adalah menganalisis media pembelajaran di sekolah khususya mengenai media pembelajaran yang berkaitan dengan kemamamouan melukis anak. Berdasarkan hasil dari analisis yang dilakukan masih belum bervariasi dalam meningkatkan kemampaun melukis anak. Selanjutnya hasil analisis tersebut dirancang dengan menggunakan media lem kanji dalam finger painting untuk meningkatkan kemampuan melukis anak.

Setelah tahap analisis, dijantukan dengan tahap perancangan (design). Pada tahap ini bertujuan untuk merancang media dari analisis yang dilakukan sebelumnya. ada tahap perancangan (design)pada tahap ini dilakukan perancangan media lem kanji. Design pembuatan media yaitu dengan menyiapkan alat dan bahan yang digunakan yaitu tepung kanji dan pewarna makanan, penulis menggunakan warna primer (merah, kuning, dan biru). Pewarna primer dapat dicampurkan kembali sehingga menghasilkan warna sekunder. Pembuatan media lem kanji, siapkan tepung kanji. Kemudian campurkan tepung kanji dengan air hingga larut. Setelah itu didihkan air dan campurkan tepung kanji yg sudah larut pada air aduk hingga mendidih. Setelah mendidih angkat, dinginkan dan tuangkan pada wadah yang sudah disiakan. Setelah dingin campurkan warna primer pada lem kanji. Siapkan kertas gambar A4. Berikut ini rancangan media lem kanji dapat dilihat pada Gambar 1. Pada tahap pengembangan mulai dibuat media yang akan dikembangkan. Pada tahap ini dilaksanakan pengembangan sesuai dengan rancangan yang sudah dibuat. Dapat dilihat pada Gambar 2. Berdasarkan hasil perhitungan ahli materi diatas, diperoleh CVR= 1 dan nilai $\mathrm{CVI}=1$, maka dapat dikatakan bahwa materi tersebut valid dan layak digunakan untuk mendukung kemampuan melukis anak. Kemudian, berdasarkan hasil perhitungan uji ahli media diatas, diperoleh nilai $\mathrm{CVR}=1$ dan nilai $\mathrm{CVI}=1$, maka dapat dikatakan bahwa media tersebut valid dan layak digunakan untuk mendukung kemampuan melukis anak. 


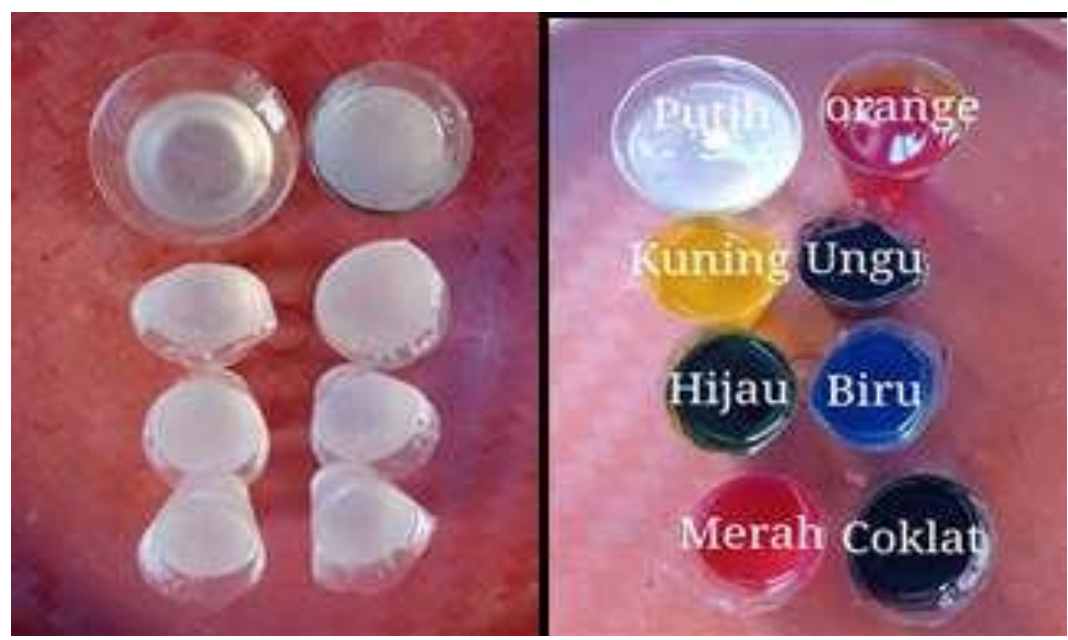

Gambar 1. Rancangan media lem kanji
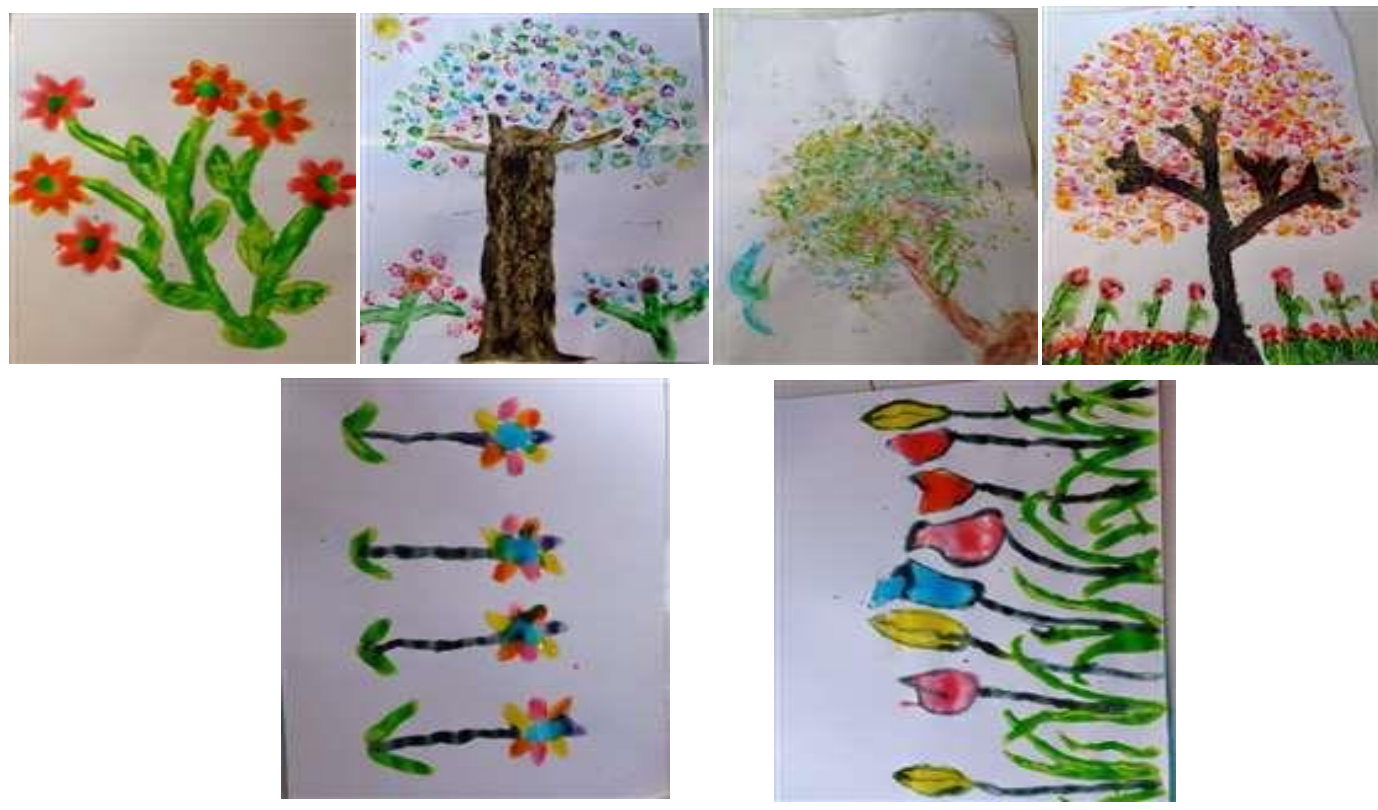

Gambar 2. Hasil Pengembangan Media Lem Kanji dalam Kegiatan Bermain Finger painting

\section{Pembahasan}

Pengembangan media lem kanji dalam kegiatan finger painting menggunakan model ADDIE dengan melalui beberapa tahap yakni: analisis (analyze), perancangan (design), pengembangan (development), sampai dengan uji validitas. Namun ada tahap yang tidak dapat terlaksanakan yaitu implementasi, dan evaluasi. Berikut ini hasil pembahasan hasil penelitian yang menggunakan model pengembangan ADDIE. Pada tahap analisis (analyze) yakni menganalisis kebutuhan anak dan analisis media. Berdasarkan dari hasil wawancara yang dilakukan kepada guru terkait dengan kebutuhan anak yang dilakukan yaitu media pembelajaran masih kurang bervariasi dalam meningkatkan kemampuan melukis anak khususnya dalam kegiatan finger painting, pada kegiatan tersebut masih menggunakan pewarna biasa yang dituangkan ke wadah kecil-kecil sehingga anak cepat bosan. Jika menggunakan media lem kanji ini sangat menarik keinginan anak untuk mencoba dan mengetahui dari tekstur lem kanji. Finger painting adalah suatu istilah melukis dengan jari (Wahyuni \& Erdiyanti, 2020). Jenis kegiatan ini merupakan suatu berkreasi dibidang datar dengan bubur berwarna sebagai bahan pewarnanya dan jari atau telapak tangan sebagai alatnya (Fauziddin \& Mufarizuddin, 2018; Fitria \& Juwita, 2018). Selanjutnya hasil dari analisis tersebut dapat dirancang menggunakan media lem kanji dalam kegiatan finger painting untuk meningkatkan kemampuan melukis anak. Tujuan melukis adalah melatih ketelitian, kesabaran dan rasa keindahan, mengembangkan kreativitas, mengenal komposisi warna, mengembangkan konsep keserasian dan ekspresi. Dalam kegiatan finger painting menggunakan media lem kanji ini, lem kanji yang sudah dikembangkan sebagai media pencampuran warna dalam kegiatan finger painting untuk meningkatkan kemampuan melukis anak (Imran 
\& Suryani, 2018; Suryani \& Haryono, 2018; Trisnayanti \& Pura, 2018). Finger painting dapat diartikan sebagai kegiatan membuat gambar yang dilakukan dengan cara menggoreskan adonan warna (bubur warna) secara langsung dengan jari tangan secara bebas diatas bidang gambar.

Tahap perancangan (design) dilakukan dalam perancangan media lem kanji berdasarkan analisis yang telah dilakukan. Desain pembuatan media yaitu dengan menyiapkan alat dan bahan yang akan digunakan, yaitu tepung kanji dan pewarna makanan, dan menggunakan warna primer (merah, kuning, dan biru). Bahan dan alat yang diperlukan antara lain kertas sebagai dasaran, bubur warna, Koran bekas, kaleng berisi air untuk cuci tangan. Alat dan bahan yang digunakan untuk Finger painting adalah pewarna untuk melukis dengan tangan, kertas manila atau kertas khusus untuk menggambar dengan tangan, kain lap, dan mangkuk-magkuk kecil sebagai tempat cat (Suciati et al., 2016). Untuk menambah variasi, pewarna primer dapat dicampurkan kembali sehingga menghasilkan warna sekunder (Cllaudia et al., 2018; Prasanti \& Fitriani, 2018; Sary, 2018). Kegiatan finger painting bertujuan untuk melatih otot-otot halus anak (Iswantiningtyas \& Wulansari, 2019; Rahimah \& Izzaty, 2018; Rohita et al., 2018). Hal ini sejalan dengan Tujuan dari Finger painting adalah melatih gerak otot-otot kecil dan kematangan syaraf, serta mengenal konsep warna primer (merah, kuning, biru) (Maghfuroh \& Putri, 2018). Lebih lanjut tujuan kegiatan finger painting untuk meningkatkan kemampuan berpikir dan kreativitas serta mengembangkan kemampuan dalam mengungkapkan nilai-nilai estetika dengan menggambar karya-karya kreatif (Hasibuan \& Ningrum, 2017). Dalam hal ini, warna yang digunakan adalah berbahan dasar tepung tapioka yang ramah lingkungan dan murah ditemuan. Pembuatan media lem kanji yakni siapkan tepung tapioka. Kemudian campurkan tepung kanji dengan air hingga larut. Setelah itu didihkan air dan campurkan tepung kanji yang sudah larut pada air aduk hingga mendidih. Setelah mendidih angkat, dinginkan dan tuangkan pada wadah yang sudah disiakan. Sifat tepung kanji apabila dicampur dengan air panas akan menjadi liat/seperti lem. Setelah dingin campurkan warna primer pada lem kanji.

Sebelum memulai kegiatan Finger painting hal-hal yang perlu dipersiapkan dan pelaksanaan yaitu : Persiapan, hal perlu disiapkan adalah sediakan kertas karton untuk melukis; beberapa mangkok yang berisi kanji yang sudah diberi berbagai macam warna primer, sediakan air untuk mencuci tangan; dan sediakan handuk dan lap untuk melap tangan setelah melakukan kegiatan finger painting. Selanjutnya pada tahap pelaksanaan, pertama sebelum memulai terlebih dahulu berikan penjelasan kepada anak tentang kegiatan yang akan dilakukan dan menjelaskan satu persatu nama-nama media yang digunakan dalam kegiatan finger painting; anak atau siswa diminta untuk mempersiapkan kertas karton; kemudian, instruksikan anak untuk mencelupkan jari-jemarinya ke dalam mangkok yang berisi kanji berwarna dan melukisnya dengan gerakan-gerakan ke kertas karton yang telah tersedia goresan jari-jemari mungil itu akhirnya menghasilkan sebuah karya lukisan yang penuh warna; jika kanji mengering. Tambah air secukupnya untuk memudahkan penggunaan kanji selanjutnya. Setelah kegiatan ini berakhir, mintalah anak untuk membersihkan tangannya dengan air, kemudian gunakan lap atau handuk untuk mengeringkan tangan anak; berikan latihan secara kontiniu.

Tahap pengembangan (development) pada tahap ini pelaksanaan pengembangan media lem kanji dalam kegiatan finger painting dengan rancangan yang telah dibuat. Melukis merupakan kegiatan mengekspresikan jiwa pelukisnya melalui media ungkap dan teknik penggarapannya berdasarkan prinsipprinsip seni rupa. Seni lukis adalah hasil karya yang merupakan curahan cita rasa subjek pencipta dengan menggunakan media karya yang berupa garis, bidang, warna, tekstur, volume, dan ruang bidang dua dimensi (Bidakwati, 2018). Beberapa manfaat melukis bagi perkembangan anak, yaitu melukis sebagai media pencampuran warna; warna sebagai alat bercerita (bahasa, visual/bentuk); melukis sebagai alat bermain; melukis dapat melatih ingatan; melukis dapat melatih berpikir komprehensif (menyeluruh); melukis merupakan media sublimasi perasaan; melukis dapat melatih keseimbangan; melukis dapat melatih kreativitas anak; melukis dapat mengembangkan rasa kesetiakawanan sosial yang tinggi (Akhyun Nafydah Siregar, 2021; Juanda, 2019; Ramdhani et al., 2019; Suryani \& Haryono, 2018; Watini, 2019). Setelah media selesai dikembangkan, proses selanjutnya dilaksanakan penilaian oleh keempat orang ahli yang meliputi dua dosen ahli media dan dua orang guru. Kemudian data validitas diperoleh dari penilaian yang telah dinilai oleh keempat ahli tersebut sehingga didapatkan nilai CVR adalah 1,00 dan CVI adalah 1,00 dengan 6 pernyataan pada instrumen materi dan 6 pernyataan pada instrumen media. Kemudian, penelitian yang dilakukan menunjukkan bahwa memperoleh hasil bahwa mengembangkan seni lukis pada anak dapat dikembangkan melalui kegiatan fingers painting (Machmud \& Alim, 2018; Sari et al., 2018). Hal tersebut dapat dilihat dari upaya penerapan yang telah lakukan dengan memberikan kegiatan membuat lukisan sesuai contoh gambar menggunakan finger painting kepada anak sebanyak 2 siklus, yang mana pada setiap siklus terdiri dari 2 pertemuan. Proses pembelajaran pada siklus I menunjukkan sebagian anak dalam membuat lukisan menggunakan fingers painting masih dibantu, ada anak yang tidak mau memegang adonan dari Finger painting. Pada pembelajaran siklus II menunjukkan hampir semua anak membuat lukisan sesuai contoh gambar menggunakan fingers painting tanpa bantuan dan semua anak mengerjakan 
kegiatan melukis yang telah diberikan. Adapun keterbatasan dalam penelitian ini yaitu hasil dari pengembangan media lem kanji dalam kegiatan finger painting tidak dapat diuji coba pada peserta didik, hal ini dikarenakan situasi covid-19 sehingga penulis hanya menghasilkan media yang layak digunakan. Maka dari dalam penelitian ini belum bisa memberikan informasi mengenai efektivitas dan keefisienan penggunaan media lem kanji dalam kegiatan finger painting untuk meningkatkan kemampuan melukis anak. Implikasi dalam penelitian ini adanya media yang memiliki kualifikasi sangat tinggi. Media yang dikembangkan dapat dimanfaatkan guru untuk mempermudah proses pembelajaran khususnya dalam meningkatkan kemampuan melukis anak. Dengan menggunakan media lem kanji dalam kegiatan finger painting kreasi dalam kegiatan belajar mengajar khususnya pada anak akan berjalan sesuai dengan yang diharapkan oleh pendidik.

\section{SIMPULAN}

Permainan Kegiatan finger painting memegang peranan penting dalam seluruh aspek perkembangan dan keterampilan anak, termasuk didalamnya adalah keterampilan melukis. Pengembangan media lem kanji dalam kegiatan finger painting memiliki tingkat validitas sangat tinggi. Hal ini ditunjukkan dengan perolehan rata-rata skor validitas media lem kanji nilai CVR mempunyai validitas sangat tinggi. Sehingga media lem kanji dalam kegiatan finger painting sangat layak digunakan untuk meningkatkan kemampuan melukis anak. Pengembangan ini diharapkan bisa menjadi referensi bagi para orang tua, guru, dan peneliti agar selalu berusaha untuk mengembangkan media pembelajaran yang dekat dengan dunia anak dan tentunya ramah lingkungan.

\section{DAFTAR RUJUKAN}

Armstrong, P. (2018). Teacher characteristics and student performance: An analysis using hierarchical linear modelling. South African Journal of Childhood Education, 5(2), 123-145. https://doi.org/10.4102/sajce.v5i2.385.

Ayuni, D., \& Setiawati, F. A. (2019). Kebun Buah Learning Media for Early Childhood Counting Ability. Jurnal Obsesi : Jurnal Pendidikan Anak Usia Dini, 3(1), 1. https://doi.org/10.31004/obsesi.v3i1.128

Bipath, K., \& Nkabinde, M. M. B. (2018). The motivational roles of heads of department in learners' performance and quality of schooling in South Africa. South African Journal of Childhood Education, 8(1), 1-8. https://doi.org/10.4102/sajce.v8i1.460.

Cllaudia, E. S., Wdiastuti, A. A., \& Kurniawan, M. (2018). Origami Game for Improving Fine Motor Skills for Children 4-5 Years Old in Gang Buaya Village in Salatiga. Jurnal Obsesi : Jurnal Pendidikan Anak Usia Dini, 2(2), 143. https://doi.org/10.31004/obsesi.v2i2.97.

Desai, Z., \& Nomlomo, V. (2014). Reflections on the development of a pre-service language curriculum for the BEd (Foundation Phase). South African Journal of Childhood Education, 4(3), 15. https://doi.org/10.4102/sajce.v4i3.227.

Fauziddin, M., \& Mufarizuddin, M. (2018). Useful of Clap Hand Games for Optimalize Cogtivite Aspects in Early Childhood Education. Jurnal Obsesi: Jurnal Pendidikan Anak Usia Dini, 2(2), 162. https://doi.org/10.31004/obsesi.v2i2.76.

Fitria, Y., \& Juwita, J. (2018). Utilization of Video Blogs (Vlogs) in Character Learning in Early Childhood. Jurnal Obsesi: Jurnal Pendidikan Anak Usia Dini, 2(2), 211. https://doi.org/10.31004/obsesi.v2i2.87.

Handayani, K. S. W., Manuaba, I. . S., \& Tirtayani, L. A. (2018). Pengaruh Finger Painting Terhadap Kemampuan Motorik Halus Anak Usia Dini Kelompok B2 Di TK Ganesha. Jurnal Pendidikan Anak Usia Dini, 6(3), 353-362. https://ejournal.undiksha.ac.id/index.php/JJPAUD/article/view/15237.

Hasibuan, R., \& Ningrum, M. A. (2017). Pengaruh Bermain Outdoor Dan Kegiatan Finger Painting Terhadap Kreativitas Anak Usia Dini. Jurnal Pendidikan (Teori Dan Praktik), 1(1), 73. https://doi.org/10.26740/jp.v1n1.p73-81.

Imran, R. F., \& Suryani, N. A. (2018). Preoperational Development of Eearly Childhood with Insectarium Media. Jurnal Obsesi: Jurnal Pendidikan Anak Usia Dini, 2(2), 267. https://doi.org/10.31004/obsesi.v2i2.88.

Iswantiningtyas, V., \& Wulansari, W. (2019). Penanaman Pendidikan Karakter pada Model Pembelajaran BCCT (Beyond Centers and Circle Time). Jurnal Obsesi : Jurnal Pendidikan Anak Usia Dini, 3(1), 110. https://doi.org/10.31004/obsesi.v3i1.106.

Juanda, J. (2019). Pendidikan Karakter Anak Usia Dini melalui Sastra Klasik Fabel Versi Daring. Jurnal Obsesi : Jurnal Pendidikan Anak Usia Dini, 3(1), 39. https://doi.org/10.31004/obsesi.v3i1.126.

Machmud, H., \& Alim, N. (2018). Multicultural Learning Model of PAUD in Coastal Areas. Jurnal Obsesi : 
Jurnal Pendidikan Anak Usia Dini, 2(2), 170. https://doi.org/10.31004/obsesi.v2i2.74.

Maghfuroh, L., \& Chayaning Putri, K. (2018). Pengaruh Finger Painting Terhadap Perkembangan Motorik Halus Anak Usia Prasekolah Di Tk Sartika I Sumurgenuk Kecamatan Babat Lamongan. Journal of Health Sciences, 10(1). https://doi.org/10.33086/jhs.v10i1.144.

Ningsih, S. (2020). Persepsi Mahasiswa Terhadap Pembelajaran Daring Pada Masa Pandemi Covid-19. JINOTEP (Jurnal Inovasi Dan Teknologi Pembelajaran): Kajian Dan Riset Dalam Teknologi Pembelajaran, 7(2), 124-132. https://doi.org/10.17977/um031v7i22020p124.

Nshimbi, J. C., Serpell, R., \& Westerholm, J. (2020). Using a phone-based learning tool as an instructional resource for initial literacy learning in rural African families. South African Journal of Childhood Education, 10(1), 1-9. https://doi.org/10.4102/sajce.v10i1.620.

Philpott, S. C., \& Muthukrishna, N. (2019). The practice of partnerships: A case study of the disabled children's action group, South Africa. South African Journal of Childhood Education, 9(1), 1-11. https://doi.org/10.4102/sajce.v9i1.729.

Prasanti, D., \& Fitriani, D. R. (2018). Building Effective Communication Between Teachers and Early Children In PAUD Institutions. Jurnal Obsesi: Jurnal Pendidikan Anak Usia Dini, 2(2), 259. https://doi.org/10.31004/obsesi.v2i2.96.

Prima, E., \& Lestari, P. I. (2018). The Improvement of The Discipline for Early Childhood Through Token Economy Technique. Jurnal Obsesi: Jurnal Pendidikan Anak Usia Dini, 2(2), 245. https://doi.org/10.31004/obsesi.v2i2.124.

Rahimah, F. Y., \& Izzaty, R. E. (2018). Developing Picture Story Book Media for Building the Self-Awareness of Early Childhood Children. Jurnal Obsesi : Jurnal Pendidikan Anak Usia Dini, 2(2), 219. https://doi.org/10.31004/obsesi.v2i2.102.

Ramdhani, S., Yuliastri, N. A., Sari, S. D., \& Hasriah, S. (2019). Penanaman Nilai-Nilai Karakter melalui Kegiatan Storytelling dengan Menggunakan Cerita Rakyat Sasak pada Anak Usia Dini. Jurnal Obsesi : Jurnal Pendidikan Anak Usia Dini, 3(1), 153. https://doi.org/10.31004/obsesi.v3i1.108.

Reed, Y. (2019). Countering linguistic imperialism with stories in the languages of africa: The african storybook initiative as a model for enabling in and out of school literacies. South African Journal of Childhood Education, 9(1), 1-8. https://doi.org/10.4102/sajce.v9i1.637.

Rohita, R., Fitria, N., Bustan, R., \& Haryadi, D. (2018). Teacher's Understanding of the Scientific Approach in the 2013 Curriculum for Early Childhood Education. Jurnal Obsesi : Jurnal Pendidikan Anak Usia Dini, 2(2), 235. https://doi.org/10.31004/obsesi.v2i2.105.

Rudolph, N., Millei, Z., \& Alasuutari, M. (2019). Corrigendum: Data practices and inequality in south african early childhood development policy: Technocratic management versus social transformation (South African Journal of Childhood Education, (2019) 9(1), a756, 10.4102/sajce.v9i1.756). South African Journal of Childhood Education, 9(1), 7682. https://doi.org/10.4102/sajce.v9i1.834.

Sary, Y. N. E. (2018). Relationship of Parenting with Child Interpersonal Intelligence in Wonokerto Village, Lumajang Regency. Jurnal Obsesi: Jurnal Pendidikan Anak Usia Dini, 2(2), 137. https://doi.org/10.31004/obsesi.v2i2.93.

Suciati, D. A. K. G., Suami, N. K., \& Ujianti, P. R. (2016). Pengaruh Kegiatan Finger Painting Berbasis Teori Lokomosi Terhadap Keterampilan Motorik Halus Anak. Jurnal Pendidikan Anak Usia Dini Undiksha, 4(2). https://ejournal.undiksha.ac.id/index.php/JJPAUD/article/viewFile/7791/5321.

Suryani, N. A., \& Haryono, M. (2018). Improvement of the Logical Intelligence Through Media Kolak (Collage Numbers) Based on Local Wisdom on Early Childhood. Jurnal Obsesi : Jurnal Pendidikan Anak Usia Dini, 2(2), 253. https://doi.org/10.31004/obsesi.v2i2.90.

Trisnayanti, Y., \& Pura, D. N. (2018). Colored plastic pulp as a collage medium in improving early childhood development. Jurnal Obsesi: Jurnal Pendidikan Anak Usia Dini, 2(2), 229. https://doi.org/10.31004/obsesi.v2i2.89.

Van Heerden, J. (2016). Quality in South African early learning centres: Mothers' and teachers' views and understanding. South African Journal of Childhood Education, 6(1), 11. https://doi.org/10.4102/sajce.v6i1.423.

Wahyuni, R., \& Erdiyanti. (2020). Meningkatkan Kemampuan Motorik Halus Anak Melalui Finger Painting Menggunakan Tepung Singkong. Murhum: Jurnal Pendidikan Anak Usia Dini, 1(1), 28-40. https://doi.org/10.37985/murhum.v1i1.5.

Watini, S. (2019). Pendekatan Kontekstual dalam Meningkatkan Hasil Belajar Sains pada Anak Usia Dini. Jurnal Obsesi: Jurnal Pendidikan Anak Usia Dini, 3(1), 82. https://doi.org/10.31004/obsesi.v3i1.111

Zaini, M., \& Soenarto, S. (2019). Persepsi Orangtua Terhadap Hadirnya Era Teknologi Digital di Kalangan Anak Usia Dini. Jurnal Obsesi: Jurnal Pendidikan Anak Usia Dini, 3(1), 254. https://doi.org/10.31004/obsesi.v3i1.127. 